\title{
Feasibility of a Low-Fidelity Pediatric Simulation- Based Continuing Education Curriculum in Rural Alaska
}

\author{
Elizabeth Sanseau ${ }^{1}$, Anita Thomas ${ }^{2}$, Elizabeth Jacob-Files ${ }^{3}$, Asela Calhoun ${ }^{4}$, Susan Romero ${ }^{5}$, Shruti
} Kant ${ }^{6}$

1. General Pediatrics: Emergency Medicine, Children's Hospital of Philadelphia, Philadelphia, USA 2. Pediatrics, Seattle Children's Hospital, Seattle, USA 3. Qualitative Health Research, University of Washington and Seattle Children's Hospital, Seattle, USA 4. Community Health Aide Program: Education, Yukon-Kuskokwim Health Corporation, Bethel, USA 5. Pediatric Critical Care: Pediatric Simulation, Alaska Native Medical Center, Anchorage, USA 6. Emergency Medicine: Pediatric Emergency Medicine, University of California, San Francisco, USA

Corresponding author: Elizabeth Sanseau, elizabeth.sanseau@gmail.com

\section{Abstract \\ Introduction}

Simulation-based continuing education (SBCE) is a widely used tool to improve healthcare workforce performance. Healthcare providers working in geographically remote and resource-limited settings face many challenges, including the development and application of SBCE. Here, we describe the development, trial, and evaluation of an SBCE curriculum in an Alaska Native healthcare system with the aim to understand SBCE feasibility and specific limitations.

\section{Methods}

The perceived feasibility and efficacy of incorporating a low-fidelity medical simulation curriculum into this Native Alaskan healthcare system was evaluated by analyzing semi-structured interviews, focus groups, and surveys over a 15-month period (August 2018 - October 2019). Subjects were identified via both convenience and purposive sampling. Included were 40 healthcare workers who participated in the simulation curriculum, three local educators who were trained in and subsequently facilitated simulations, and seven institutional leaders identified as "key informants." Data included surveys with the Likert scale and dichotomous positive or negative data, as well as a thematic analysis of the qualitative portion of participant survey responses, focus group interviews of educators, and semi-structured interviews of key informants. Based on these data, feasibility was assessed in four domains: acceptability, demand, practicality, and implementation.

\section{Results}

Received 04/23/2020 Review began 05/10/2020 Review ended 05/14/2020 Published 05/26/2020

(c) Copyright 2020 Sanseau et al. This is an open access article distributed under the terms of the Creative Commons Attribution License CC-BY 4.0., which permits unrestricted use, distribution, and reproduction in any medium, provided the original author and source are credited.
Stakeholders and participants had positive buy-in for SBCE, recognizing the potential to improve provider confidence, standardize medical care, and improve teamwork and communication, all factors identified to optimize patient safety. The strengths listed support feasibility in terms of acceptability and demand. A number of challenges in the realms of practicality and implementation were identified, including institutional buy-in, need for a program champion in a setting of staff high turnover, and practicalities of scheduling and accessing participants working in one system across a vast and remote geographic region. Participants perceived the simulations to be effective and feasible.

\section{Conclusion}

While simulation participants valued an SBCE program, institutional leaders and educators identified veritable obstacles to the practical implementation of a structured program. Given the inherent challenges of this setting, a traditional simulation curriculum is unlikely to be fully feasibly integrated. However, due to the overall demand and social acceptability expressed by the participants, innovative ways to deliver simulation should be developed, trialed, and evaluated in the future.

Categories: Emergency Medicine, Medical Simulation, Pediatrics

Keywords: simulation-based medical education, curriculum planning, continuing professional development, pedagogical practice, feasibility assessment, community health aides and practitioners, native alaska, rural medicine, pediatric emergency medicine

\section{Introduction}

Simulation as a training tool is increasingly utilized in medical education, as it is demonstrated to be effective in improving patient safety and reducing health care costs [1-3]. The degree to which the simulation training reflects reality is described along a continuum of low- to high-fidelity, which can be 
adjusted according to the learning objectives of the simulation [4]. High-fidelity is not necessarily superior to low-fidelity to achieve educational learning objectives [5-6]. Barriers to incorporating high-fidelity simulation include insufficient availability, cost, lack of access and trained faculty, and time constraints [7]. While a low-fidelity simulation program is inexpensive and requires little to no additional equipment to implement, it does require at least the eight critical factors identified by the Joint Commission Journal on Quality and Patient Safety: science, staff, supplies, space, support, systems, success, and sustainability [8].

Geographic and ethnic disparities in healthcare service more heavily impact vulnerable populations of infants and children when compared to adults, and death rates for American Indian/Alaska Native (AI/AN) infants and children, the majority of those who reside in a rural area, are nearly three times higher than for Caucasians. Overall, the pediatric death rate for AI/AN youths to 19 years of age was 73.2 as compared with 29.1 for Caucasian youths from 1999-2009, with the AI/AN pediatric death rates highest for the Alaska region across all age categories $(\mathrm{P}<0.1)[9]$. Influenza and pneumonia rank as the highest causes of mortality in Alaska [10].

The backbone of the healthcare delivery workforce in the Southwest Native Alaska villages is the Community Health Aide/Practitioner (CHA/P), with hospital personnel, including nurses, advanced practitioners, and physicians, staffing the sub-regional centers and regional hospital. The CHA/Ps practice broad-spectrum medicine, including primary and preventative, chronic, acute, and emergency services. They service 47 Alaska Native villages surrounding the regional city hub, with approximately 25,000 residents, spanning a river delta region more than 50,000 square miles in size [11-14]. The land consists of coastal wetlands, tundra, and mountains and is accessible off the traditional road system via plane, boat, dog sled, or snow machine, colloquially known as the "bush." The approximately $170 \mathrm{CHA} / \mathrm{Ps}$ working in this region are often the sole source of healthcare in the village. They report to a supervising provider located in the sub-regional clinic or main hospital hub and must be prepared to handle any emergency medical situation that arises.

The CHA/Ps, nurses, and providers are required to complete continuing education (CE) as part of the maintenance of certification. Given the geographically remote and resource-limited setting of the hospital, this usually means traveling far, which is time and cost-intensive. CHA/Ps have access to CE boot camps in the regional hospital and until now, their simulation experience is limited to simple procedural task trainers and standardized certificate courses (e.g. Acute Life Support).

The inspiration for this project arose from a direct request for simulation-based education from experienced CHA/Ps working in a sub-regional clinic setting in Southwest Alaska. Given the unique job description of these providers, including specific medical knowledge, skills, and teamwork/communication capabilities required for success on the job, simulation-based education seems like a potentially suitable and beneficial endeavor [15]. The authors subsequently conducted an assessment to capture the specific needs of this community. Providers reported a lack of a formal simulation program and a desire to have one. Specifically, those surveyed requested scenarios for pediatric respiratory distress, likely in response to the disproportionately high rates of respiratory infections and pulmonary chronic disease in the region [16].

Given the declared need for an SBCE program for these providers working with this population with significant health disparities, the authors developed and piloted a low-fidelity simulation curriculum for pediatric respiratory distress scenarios common in the region [17]. The simulations were launched as part of this study developed with the aim to assess the feasibility of the curriculum in the domains of acceptability, demand, practicality, and implementation, in addition to the perceived efficacy. The feasibility study methodology was selected because community partnerships needed to be established and a paucity of prior studies exist that are relevant to the target population [18]. This study was evaluated in a real-world setting, recognizing the difficulties of conducting an internally validated, highly controlled efficacy trial in a community site. Local practitioners and community members were actively involved in meaningful ways, from program inception through design and execution.

\section{Materials And Methods}

\section{Study design, participants, sample size, and sampling}

Two CE simulation-based boot camps were held for CHA/Ps and one day of simulations was held for hospital-based nurses and emergency room (ER) technicians facilitated by outside simulation educators (ES, $\mathrm{SR}$ ). Instructors were one pediatrician who worked at the local institution (ES) and one traveling pediatric critical care nurse practitioner (SR), each with over three years of simulation facilitation experience. A convenience sample of $11 \mathrm{CHA} / \mathrm{Ps}, 15$ nurses, and two ER technicians participated in the sessions and were invited to submit survey responses evaluating their perception of the effectiveness and feasibility of the activity in the domains of acceptability, demand, practicality, and implementation. These sessions led by outside facilitators are grouped together as Survey Group \#1.

In an effort to implement a sustainable program, we trained local educators of the hospital nursing staff and the CHA/Ps simulation facilitation and debriefing with a one-day workshop and subsequently asked them to facilitate two simulation boot camp days with a total of $12 \mathrm{CHA} / \mathrm{P}$ participants. All participants received official CE credit for their participation. These sessions facilitated by trained local educators are grouped 


\section{Cureus}

together as Survey Group \#2.

Of the five local educators who participated in the training, only three were able to subsequently facilitate the two simulation days due to competing work demands, with one of them facilitating both sessions. Following these simulation days, we conducted focus groups of the facilitators to explore their perceptions of the tool. This is captured as Focus Groups \#1 and \#2.

In addition, seven local "key informant" hospital leaders were identified via purposeful sampling to participate in semi-structured interviews guided with the intent to explore their perception of the feasibility of implementing a simulation program at their institution.

These data collection points are summarized in Figure 1.

\begin{tabular}{|c|c|c|c|c|c|}
\hline August 2018 & \multicolumn{2}{|c|}{ December 2018} & \multicolumn{2}{|c|}{ August 2019} & October 2019 \\
\hline $\begin{array}{l}\text { Survey } \\
\text { Group \#1: } \\
8 / 23 / 18 \\
(n=8) \\
\text { CHA/Ps }\end{array}$ & \begin{tabular}{|l|} 
Survey \\
Group \#1: \\
$10 / 9 / 18$ \\
$(n=17)$ \\
Nurses/ER \\
technicians
\end{tabular} & $\begin{array}{l}\text { Survey } \\
\text { Group \#1: } \\
12 / 13 / 18 \\
(n=3) \\
\text { CHA/Ps }\end{array}$ & $\begin{array}{l}\text { Train-The- } \\
\text { Trainer } \\
4 / 16 / 19 \\
5 \text { Local } \\
\text { educators }\end{array}$ & $\begin{array}{l}\text { Survey } \\
\text { Group \#2: } \\
8 / 27 / 19 \\
(n=6) \\
\text { CHA/Ps }\end{array}$ & $\begin{array}{l}\text { Survey } \\
\text { Group \#2: } \\
10 / 22 / 19 \\
(n=6) \\
\text { CHAP/s }\end{array}$ \\
\hline \multicolumn{3}{|c|}{$\begin{array}{l}\text { Semi-Structured Interviews: } \\
8-12 / 2018 \\
(n=7) \\
\text { Key-informants }\end{array}$} & & $\begin{array}{l}\text { Focus } \\
\text { Group \#1: } \\
8 / 27 / 19 \\
(n=2) \\
\text { Local } \\
\text { educators }\end{array}$ & $\begin{array}{l}\text { Focus } \\
\text { Group \#2: } \\
\text { 10/22/19 } \\
(n=2) \\
\text { Local } \\
\text { educators }\end{array}$ \\
\hline
\end{tabular}

\section{FIGURE 1: Timeline}

CHA/Ps: Community Health Aide/Practitioners; ER: Emergency Room

\section{Data collection \& analysis}

Simulation participants were surveyed on their perception of the effectiveness of the exercise on the basis of realism, usefulness in reviewing resuscitation and medical management skills, and whether the debrief felt safe and relevant, using the 5 -point Likert scale ( 1 = strongly disagree, 3 = neutral, $5=$ strongly agree) and the mean, standard deviation, median, and ranges were calculated [19]. See Table 1.

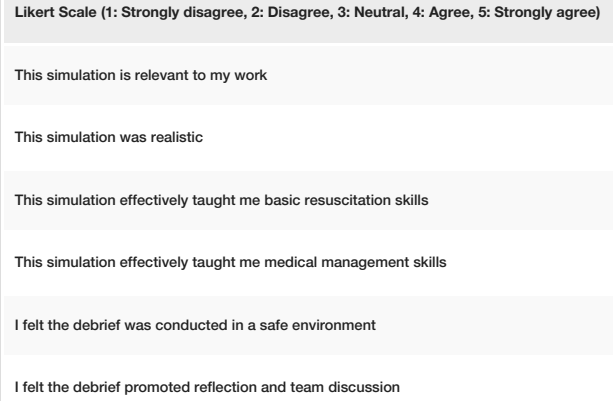

TABLE 1: Post-simulation questionnaire of participants

Feasibility data were collected as dichotomous yes/no answers and qualitative responses to participant surveys (Table 2), as well as key informant, semi-structured interviews (Table 3) and educator focus group interviews (Table 4). The questions were framed to assess the four feasibility dimensions of acceptability, demand, practicality, and implementation. The content of the qualitative responses, interviews, and focus groups was analyzed. A realist thematic analysis approach was used to establish categories of concepts and themes, focusing on reporting the experiences, meanings, and realities across respondents [20]. The 


\section{Cureus}

codebook, which contained mostly semantic themes, was developed directly from the text [21]. In the final round of coding, excerpts from each major theme were used to refine and define sub-themes in the context of the four feasibility domains listed above.

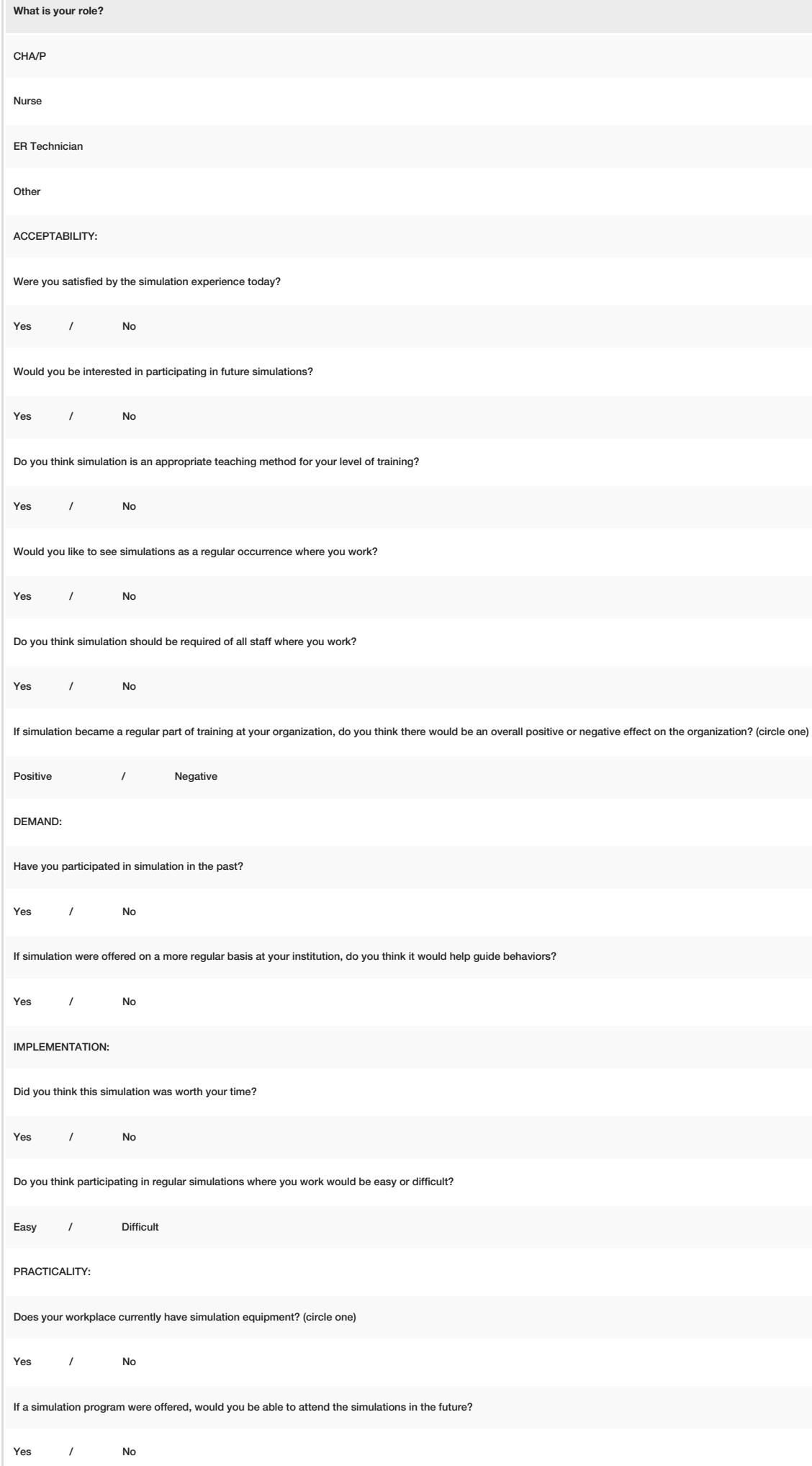

\section{TABLE 2: Post-simulation participant survey}




\section{Cureus}

What is your role?

ACCEPTABILTYY:

Is the concept of a new simulation program at YKHC attractive? (circle one)

Yes $/$ No

Please explain:

Do you think simulation is an appropriate teaching method for this population? (circle one)

Yes 1 No

Please explain:

What might be some positive effects of implementing a simulation program?

What might be some negative effects of implementing a simulation program?

DEMAND:

Do you think there is a demand for simulation at YKHC? (circle one)

Yes,, No

Please explain:

Do you think regular simulations with hospital staff / students / CHA's would guide behaviors?

Yes 1 No

Please explain:

If a simulation program were developed for use at YKHC, would there be institutional buy-in to implement it?

Yes $\quad$ No

If yes, how so? (i.e.: CME, etc.)?

IMPLEMENTATION:

Do you think implementing a simulation program would be easy or difficult?

If easy, please explain:

If difficult, please explain

What would be barriers/limitations to implementing a structured simulation program? (i.e.: resources, community buy-in, etc.)

PRACTICALITY:

Do you think simulation would have a positive or negative effect on the participants? (circle one)

Positive , Negative

If positive, please explain:

If negative, please explain:

If a simulation program were developed for $\mathrm{YKHC}$, do you think the program could be carried out and sustained without outside interventions moving forward?

ACCEPTABILITY:

Is the concept of a new simulation program at YKHC attractive? (circle one)

Yes , No

Please explain:

Do you think simulation is an appropriate teaching method for this population? (circle one)

Yes, No

Please explain:

What might be some positive effects of implementing a simulation program? 


\section{Cureus}

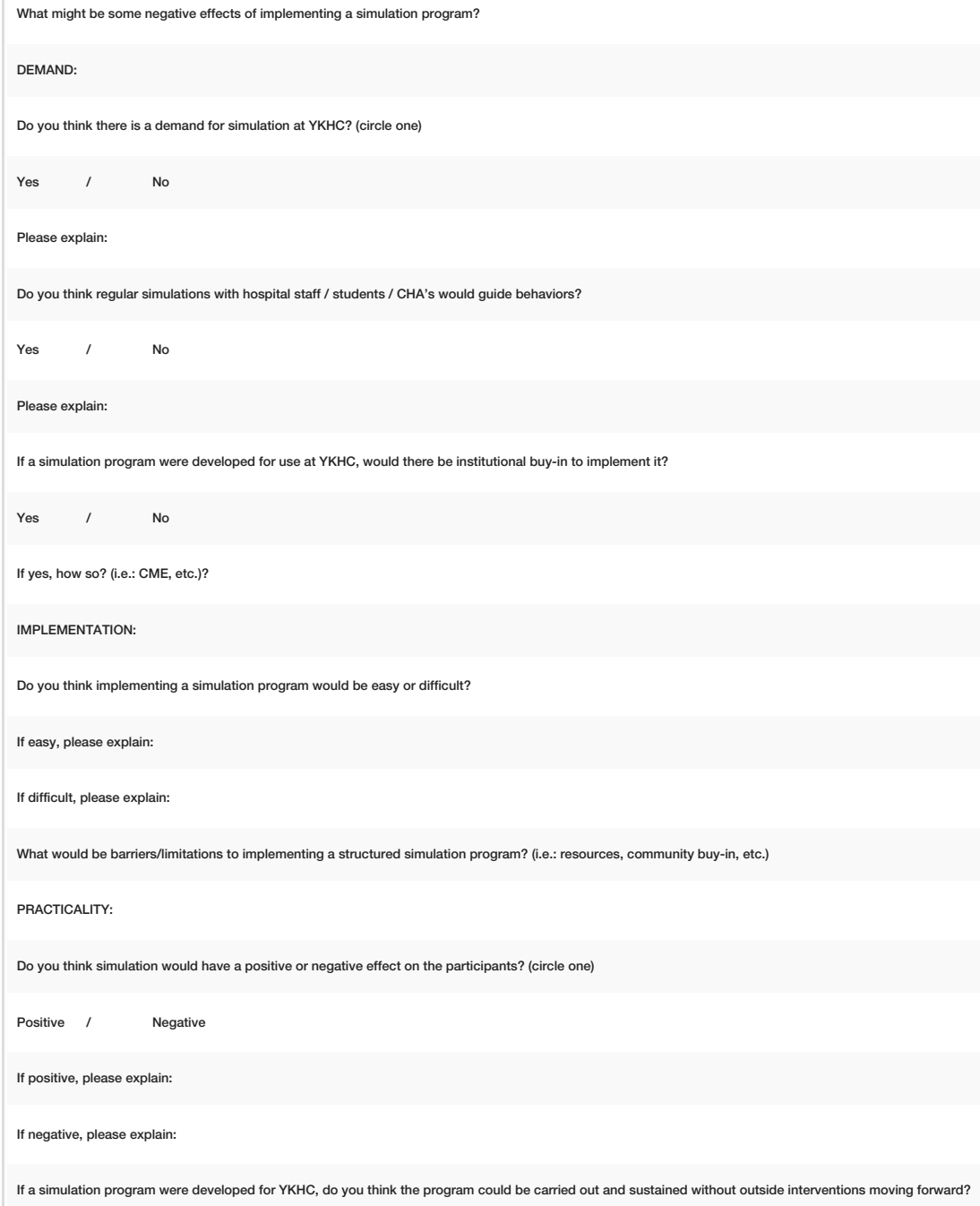

TABLE 3: Key informant semi-structured interview guide

CHA: Community Health Aide; CHA/Ps: Community Health Aide/Practitioners; CME: Continuing Medical Education; ER: Emergency Room; YKHC: Yukon-Kuskokwim Health Corporation 


\section{Cureus}

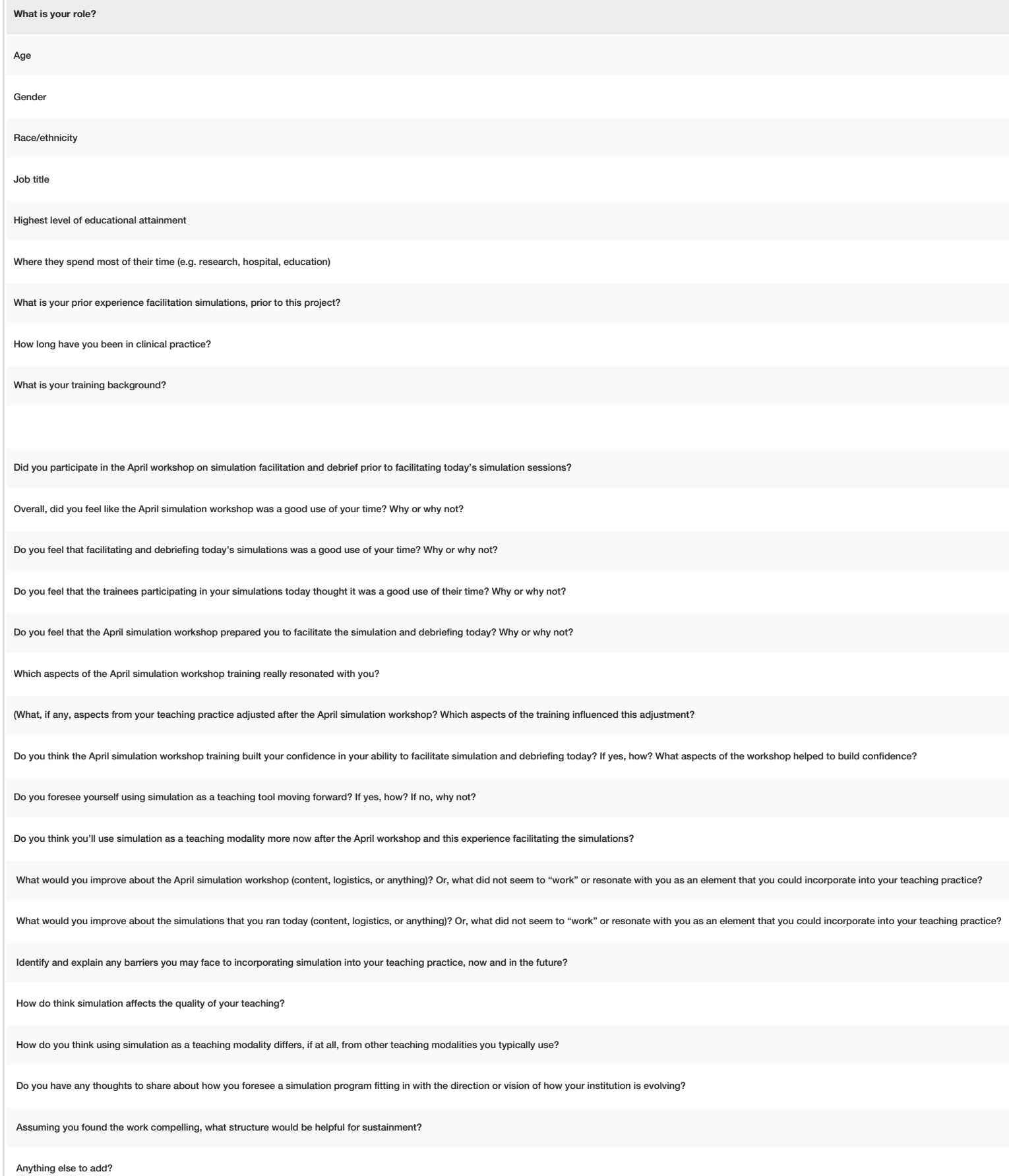

TABLE 4: Focus-group interview guide

Acceptability was translated as the perception that the SBCE would be both desirable and culturally appropriate, with the mostly Alaska Native population that makes up the CHA/P workforce, the nursing staff, and educators in a hospital known to have a high staff turnover rate. Demand was operationalized as the perceived need for the SBCE. Practicality was linked to the costs (financial and temporal) associated with the program. Implementation was evaluated as the likelihood that the intervention could be fully integrated into the local CE coursework without needing ongoing outside resources.

This investigation was approved by the Seattle Children's Hospital Institutional Review Board and the Yukon-Kuskokwim Health Corporation (YKHC) Human Subjects Committee.

\section{Results}




\section{Cureus}

\section{Participants}

Five local educators participated in a simulation facilitation workshop and three of the five subsequently led two simulation days. These three educators train CHA/Ps or nurses, average over 25 years of clinical nursing experience each, and have simulation experience in facilitating the Advanced Cardiac Life Support (ACLS) course. Of the 40 simulation participants, 23 were CHA/Ps, 15 nurses, and two ER technicians. Twelve of the CHA/Ps participated in simulations facilitated by the newly trained local educators (Survey Group \#2) while the other 28 participants were led by external simulation facilitators (Survey Group \#1). The seven key informants that participated in the semi-structured interviews included three physicians, two doctorate, and two nurse administrators; all informants were selectively identified due to their leadership roles in the hospital system, Community Health Aide Program, and nursing/provider education.

\section{Effectiveness outcomes}

All 40 simulation participants completed the post-simulation questions assessing feasibility and effectiveness. When asked to evaluate the effectiveness of the simulations on the Likert scale across six questions, the curriculum received a median of 5, mean of 4.59, standard deviation of 0.23 , and range 3-5. When comparing the responses of participants with outside facilitators (Survey Group \#1) vs local newly trained simulation facilitators (Survey Group \#2), the mean (standard deviation) was only slightly higher (4.75 (0.19) vs $4.42(0.14)$ ) and the range of responses was respectively wider (3-5 vs 4-5) (Table 5).

\begin{tabular}{|c|c|c|c|c|}
\hline \multicolumn{5}{|l|}{ ikert Scale: 1 = Strongly disagree, 2} \\
\hline Statement & Participants & Mean (Standard Deviation) & Median & Range \\
\hline This simulation is relevant to my work (Survey Group \#1) & $\mathrm{CHA} / \mathrm{P}(\mathrm{n}=11)$ & $4.74(0.47)$ & 5 & $4-5$ \\
\hline This simulation is relevant to my work (Survey Group \#2) & $\mathrm{CHA} / \mathrm{P}(\mathrm{n}=12)$ & $4.58(0.51)$ & 5 & $4-5$ \\
\hline \multirow{2}{*}{ This simulation was realistic (Survey Group \#1) } & CHA/P & $4.27(0.79)$ & \multirow{2}{*}{5} & \multirow{2}{*}{$3-5$} \\
\hline & Nurse, ER Technician & $4.82(0.39)$ & & \\
\hline This simulation was realistic Survey Group \#2) & CHA/P & $4.25(0.62)$ & 5 & $3-5$ \\
\hline \multirow{2}{*}{ This simulation effectively taught me basic resuscitation skills (Survey Group \#1) } & CHA/P & $4.64(0.50)$ & \multirow{2}{*}{5} & \multirow{2}{*}{$3-5$} \\
\hline & Nurse, ER Technician & $4.59(0.71)$ & & \\
\hline This simulation effectively taught me basic resuscitation skills (Survey Group \#2) & $\mathrm{CHA} / \mathrm{P}$ & $4.33(0.49)$ & 4 & $4-5$ \\
\hline \multirow{2}{*}{ This simulation effectively taught me medical management skills (Survey G } & CHA/P & $4.73(0.47)$ & \multirow{2}{*}{5} & \multirow{2}{*}{$4-5$} \\
\hline & Nurse, ER Technician & $4.82(0.39)$ & & \\
\hline This simulation effectively taught me medical management skills (Survey Group \#2) & CHA/P & $4.33(0.49)$ & 4 & $4-5$ \\
\hline \multirow{2}{*}{ If felt the debrief was conducted in a safe environment (Survey Group } & CHA/P & $4.72(0.47)$ & \multirow{2}{*}{5} & \multirow{2}{*}{$4-5$} \\
\hline & Nurse, ER Technician & $4.94(0.24)$ & & \\
\hline I felt the debrief was conducted in a safe environment (Survey Group \#2) & CHA/P & $4.42(0.51)$ & 4 & $4-5$ \\
\hline \multirow{2}{*}{ I felt the de } & CHA/P & $4.81(0.40)$ & \multirow{2}{*}{5} & \multirow{2}{*}{$4-5$} \\
\hline & Nurse, ER Technician & $4.94(0.24)$ & & \\
\hline I felt the debrief promoted reflection and team discussion (Survey Group \#2) & CHA/P & $4.58(0.51)$ & 5 & $4-5$ \\
\hline Group \#1 Total & $n=28$ & $4.75(0.19)$ & 5 & $3-5$ \\
\hline Group \#2 Total & $n=12$ & $4.42(0.14)$ & 4.5 & $4-5$ \\
\hline Total Combined & 40 & $1.59(0.23)$ & 5 & $3-5$ \\
\hline
\end{tabular}

\section{TABLE 5: Participant feedback on simulation effectiveness}

CHA/P: Community Health Aide/Practitioners; ER: Emergency Room 


\section{Feasibility outcomes}

When asked dichotomous positive/negative feasibility questions, the CHA/Ps responded 100\% positive to acceptability, demand, and practicality questions and $91 \%$ positive to the implementation question. The nurses and ER technicians responded $98 \%$ positive to acceptability, $100 \%$ demand, $79 \%$ practicality, and $94 \%$ implementation. The key informants responded $100 \%$ positively to acceptability, practicality, and implementation, and $95 \%$ positively to demand (Table 6).

\begin{tabular}{|c|c|c|c|}
\hline Feasibility Domain & Participant & \% YES & \% No \\
\hline \multirow{3}{*}{ Acceptability } & CHAPP & 100 & 0 \\
\hline & Nurse, ER Technician & 98 & 2 \\
\hline & Key informant & 100 & 0 \\
\hline \multirow{3}{*}{ Demand } & CHA/P & 100 & 0 \\
\hline & Nurse, ER Techniciaan & 100 & 0 \\
\hline & Key informant & 95 & 5 \\
\hline \multirow{3}{*}{ Practicality } & CHA/P & 100 & 0 \\
\hline & Nurse, ER Technician & 79 & 21 \\
\hline & Key informant & 100 & 0 \\
\hline \multirow{3}{*}{ Implen } & CHA/P & 91 & 9 \\
\hline & Nurse, ER Technician & 94 & 6 \\
\hline & Key informant & 100 & 0 \\
\hline
\end{tabular}

TABLE 6: Survey responses to feasibility questions (Yes / No)

CHA/P: Community Health Aide/Practitioners; ER: Emergency Room

The following themes emerged upon qualitative analysis.

In the acceptability domain, themes emerged across all respondents that simulation-based active learning is a useful and well-received way to prepare for responding to emergencies. Educators also note that collaborating on simulation facilitation enhanced cross-institutional collegiality.

In the demand realm, themes expressed across all respondents that this type of education is needed to standardize medical care and improve teamwork/communication skills and healthcare worker confidence, which has the potential to improve patient outcomes/safety.

In the practicality realm, themes emerged from the key informants and educators that funding and physical space would be necessary to realize a program and scheduling would be a challenge for a workforce spanning a large rural geographic region. Participants expressed they would participate if it was supported and expected by their managers, if continuing education credits were allotted, and if it fits into the standard workday.

In the implementation realm, themes emerged from educators and some key informants that there would need to be broader institutional buy-in to enforce a program with an allotted local champion responsible for it, especially given the reality of high staff turnover in the region. While educators felt comfortable running simple task-training simulations and leading ACLS courses as they had done prior to this project, they expressed discomfort with facilitating and debriefing more complex medical scenarios after just one workshop and two days of direct observation and feedback.

All respondents suggested the possibility of utilizing the robust telecommunication network already in place in the region to overcome barriers to accessing a high-quality, sustainable SBCE. CHA/Ps overwhelmingly asked for simulations "in-situ" in the village and sub-regional clinics, where the bulk of their medical practice takes place. They note their daily experience with telemedicine, tele-education, and teleconferencing, and suggest the potential to offer this training via this established telecommunication system to overcome the acknowledged barriers of time, space, and resources. See Tables 7-8 for sample quotations. 


\section{Cureus}

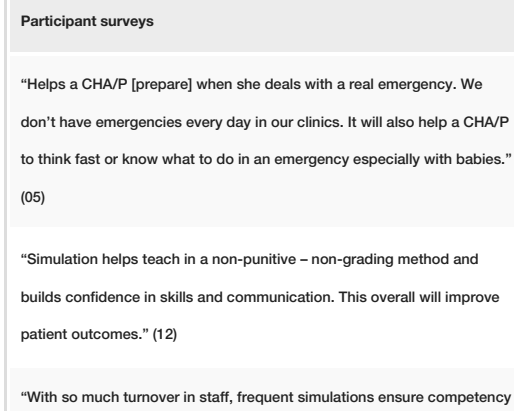

\section{Educator focus groups}

"I think it helps them learn better when they can actually practice

hands-on. I think they can develop more confidence from doing hands-

on learning, and I think they are bored to tears when we just talk at them." (48)

"[SIM affects my teaching] Undoubtedly. It's hard, one if you're

studying adult education, adult learning, to imagine quality teaching

without it. If you really want retention." (49)

"I am an educator and I believe it to be the most effective form of education." (49)
Key informant semi-structured interviews

"This is a project that I have wanted to put in place for some time, it will

give great benefit to both new and seasoned Health Aides in their practice, in a safe environment that is conducive to learning and retention skills."

"We don't currently have this program and I think with staff turnover and new staff starting all the time, this could be a valuable way to improve our patient care and safety." (31)

"I think this concept has the potential to improve both patient care and patient safety." (31)

\section{TABLE 7: Example quotations: acceptability and demand}

CHA/P: Community Health Aide/Practitioner; SIM: Simulation

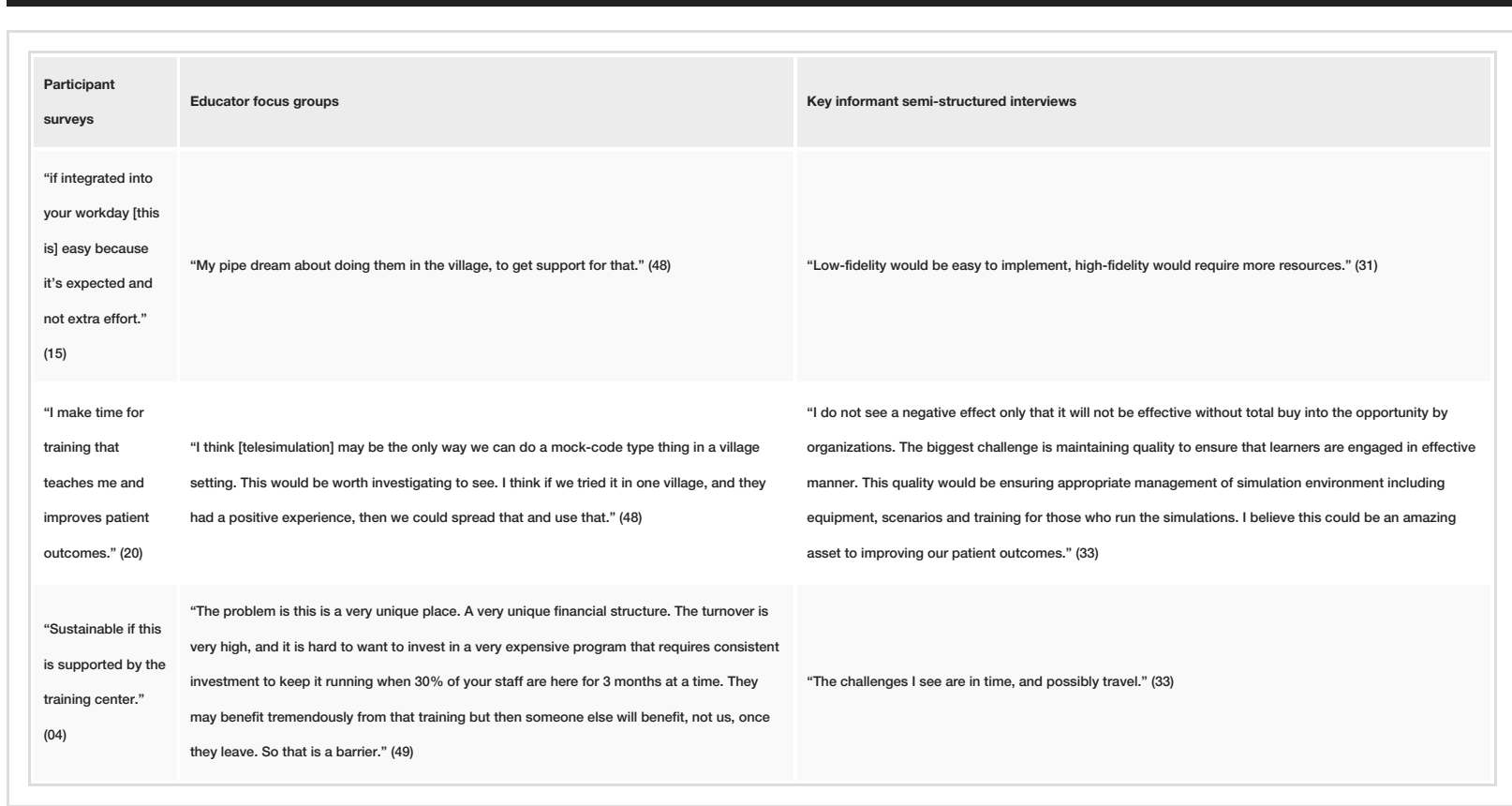

TABLE 8: Example quotations: practicality and implementation

\section{Discussion}

We were able to conduct a simulation program that served a unique and disparate group of participants who practice broad-spectrum "bush" medicine. Despite widespread acceptability and demand, the full integration of a practical and implementable SBCE program would require larger institutional buy-in, established champion(s), funding, and creativity in overcoming scheduling and access issues.

Our team prioritized the training of local educators in simulation facilitation and created opportunities to practice these newly acquired skills with on-the-ground mentorship in an effort to integrate the didactic method into the existing $\mathrm{CHA} / \mathrm{P}$ training program. Integration is another feasibility domain, operationalized as the level of system change needed to integrate a new program or process into an existing infrastructure or program [18]. The local educators expressed insecurity in their facilitation skills after just one day of simulation training and only two subsequent mentored practice sessions. Interestingly, the simulation participants gave overwhelmingly positive feedback to these sessions, reflected in their Likert scale perceived effectiveness scores and open-ended survey responses. The discrepancy between local educator confidence and positive participant feedback should be further explored in order to create a feasible program.

Participants, key informants, and educators alike overwhelmingly brought up the possibility of harnessing the power of the established telecommunication network unique to this setting to overcome the perceived 
barriers to integrating an SBCE curriculum. One possible solution to enhancing the feasibility of an SBCE program for providers in this remote and resource-limited setting is leveraging the telecommunication system to introduce telesimulation. Telesimulation is a replicable, low-cost, and robust tool that optimizes learning and instructor training with simulation in resource-limited settings [22]. Tele-co-debriefing has been utilized in transcontinental settings for simulation faculty development and remotely facilitated simulation has been shown to be as effective as traditional, locally facilitated simulation [23]. Future projects might consider developing a telesimulation program. The program could utilize a network of simulationists from more resourced areas to help co-facilitate remotely, with the intention to improve access to high-quality CE while continuing to build capacity in the local simulation facilitators themselves. Remote co-facilitation may be one way to provide ongoing mentorship to the local newly trained educators in an effort to enhance their comfort in simulation facilitation. Future studies can focus on demonstrating impacts on learners, facilitators, clinical outcomes, and other quality improvement metrics.

This study is limited by a small convenience sample size. Given that we chose to conduct a feasibility study in a real-life, busy hospital with the actual participants that would ultimately be involved in the proposed SBCE, the authors felt this was necessary. However, we acknowledge the disadvantage that the convenience sample does not accurately represent the entire population of providers seeking CE in this broader geographic region. Thus, feasibility results might be skewed and may represent a barrier. We limited the evaluation of the simulation to learner perceptions of utility and did not directly evaluate the impact on knowledge, acquisition, or communication skills. Pre- and post-tests and/or videotaping with subsequent review are ways to enhance the evaluation piece of simulation in the future.

\section{Conclusions}

SBCE was found to be acceptable and in demand. Local educators were trained and facilitated simulations that were well-received by participants. While we were able to implement this research project, we uncovered barriers to the true integration of this SBCE program moving forward. A suggested, innovative solution to overcome some feasibility barriers was telesimulation. Future initiatives might consider developing a telesimulation tool to integrate into the established telecommunication system in the region. Studies can build upon this assessment and consider ways to innovate simulation delivery while studying the impact on cost, provider competence, and, ultimately, patient outcomes. The authors herein conclude that a formal low-fidelity SBCE program may be feasible within this rural Alaska Native healthcare system if the acknowledged barriers are addressed creatively.

\section{Additional Information \\ Disclosures}

Human subjects: Consent was obtained by all participants in this study. Seattle Children's Hospital issued approval STUDY00001348. Yukon-Kuskokwim Health Corporation Human Subjects Committee, Approval Number 20.06.01. Animal subjects: All authors have confirmed that this study did not involve animal subjects or tissue. Conflicts of interest: In compliance with the ICMJE uniform disclosure form, all authors declare the following: Payment/services info: Rasmuson Foundation provided a Tier 1 Grant to fund this project. Financial relationships: All authors have declared that they have no financial relationships at present or within the previous three years with any organizations that might have an interest in the submitted work. Other relationships: All authors have declared that there are no other relationships or activities that could appear to have influenced the submitted work.

\section{Acknowledgements}

The authors would like to acknowledge the Rasmuson Foundation for providing a Tier 1 Grant to fund this project. In addition, we would like to express our gratitude to the following people, without whom this study would not have been possible: Amber Amsden, RN, ANMC, Anchorage, AK; Rachel Umoren, MD, Seattle Children's Hospital, WA; John Morris, BS, BSN, RN, Yukon-Kuskokwim Health Corporation, Bethel, AK; and Rachelle White, BSN, RN, CWCN, Bethel Outreach Term Instructor, University of Alaska Anchorage School of Nursing Program, Bethel, AK.

\section{References}

1. Barry Issenberg S, Mcgaghie WC, Petrusa ER, Lee Gordon D, Scalese RJ: Features and uses of high-fidelity medical simulations that lead to effective learning: a BEME systematic review. Med Teach. 2009, 1:10-28. 10.1080/01421590500046924

2. Al-Elq AH: Simulation-based medical teaching and learning. J Family Community Med. 2010, 1:35-40.

3. Akaike M, Fukutomi M, Nagamune M, Fujimoto A, Tsuji A, Ishida K, Iwata T: Simulation-based medical education in clinical skills laboratory. J Med Invest. 2012, 59:28-35. 10.2152/jmi.59.28

4. Maran NJ, Glavin RJ: Low-to high-fidelity simulation-a continuum of medical education? . Med Educ. 2003, 37:22-28. 10.1046/j.1365-2923.37.s1.9.x

5. Massoth C, Röder H, Ohlenburg H, Hessler M, Zarbock A, Pöpping DM, Wenk M: High-fidelity is not superior to low-fidelity simulation but leads to overconfidence in medical students. BMC Med Educ. 2019, 19:29. 10.1186/s12909-019-1464-7

6. Munshi F, Lababidi H, Alyousef S: Low-versus high-fidelity simulations in teaching and assessing clinical 
skills. J Taibah Univ Med Sci. 2015, 10:12-15. 10.1016/j.jtumed.2015.01.008

7. Chinnugounder S, Hippe DS, Maximin S, O’Malley RB, Wang CL: Perceived barriers to the use of highfidelity hands-on simulation training for contrast reaction management: why programs are not using it. Curr Probl Diagn Radiol. 2015, 44:474-478. 10.1067/j.cpradiol.2015.03.006

8. Lazzara EH, Benishek LE, Dietz AS, Salas E, Adriansen DJ: Eight critical factors in creating and implementing a successful simulation program. Jt Comm J Qual Patient Saf. 2014, 40:21-29. 10.1016/S15537250(14)40003-5

9. Wong CA, Gachupin FC, Holman RC, MacDorman MF, Cheek JE, Holve S, Singleton RJ: American Indian and Alaska native infant and pediatric mortality, United States, 1999-2009. Am J Public Health. 2014, 320:8. 10.2105/AJPH.2013.301598

10. Singleton RJ, Holman RC, Folkema AM, Wenger JD, Steiner CA, Redd JT: Trends in lower respiratory tract infection hospitalizations among American Indian/Alaska Native children and the general US child population. J Pediatr. 2012, 161:296-302. 10.1016/j.jpeds.2012.02.004

11. Thorsteinson LK, Becker PR, Hale DA: Yukon Delta: a synthesis of information . Anchorage, AK (USA): National Ocean Service, Ocean Assessments Division, Report No. PB-90-142746/XAB. 1989, 1:1-102. Accessed: April 23, 2020: https://www.osti.gov/biblio/7152840.

12. U.S. Census Bureau, 2010 Census of Population and Housing: Population and Housing Unit Counts, CPH-21, United States Summary. Government Printing Office, Washington, DC; 2012.

13. About YKHC. Yukon-Kuskokwim Health Corporation. Accessed: April 23, 2020: https://www.ykhc.org/story/about-ykhc.

14. Category:overview of YKHC Medical Practices. (2020). Accessed: April 6, 2020: http://ykhealth.org/wiki/Category:Overview_of_YKHC_Medical_Practices.

15. Shapiro MJ, Morey JC, Small SD, et al.: Simulation based teamwork training for emergency department staff: does it improve clinical team performance when added to an existing didactic teamwork curriculum? BMJ Qual Saf. 2004, 13:417-421. 10.1136/qshc.2003.005447

16. Singleton R, Morris A, Redding G, et al:: Bronchiectasis in Alaska Native children: causes and clinical courses. Pediatr Pulmonol. 2000, 1002:182-187. 10.1002/(SICI)1099-0496(200003)29:3\%3C182::AIDPPUL5\%3E3.0.CO;2-T

17. Sanseau E, Reid J, Stone K, Burns R, Uspal N: Pediatric simulation cases for primary care providers: asthma, anaphylaxis, seizure in the office. MedEdPORTAL. 2018, 14:1. Accessed: April 6, 2020: 10.15766/mep_23748265.10762

18. Bowen DJ, Kreuter M, Spring B, et al.: How we design feasibility studies. Am J Prev Med. 2009, 36:452-457. 10.1016/j.amepre.2009.02.002

19. Likert R: A technique for the measurement of attitudes . Archives of Psychology. 1932, 140:1-55.

20. Virginia Braun V, Clarke E: Using thematic analysis in psychology . Qual Res Psychol. 2006, 3:77-101. 10.1191/1478088706qp063oa

21. Boyatzis RE: Transforming Qualitative Information: Thematic Analysis and Code Development. Sage Publications, Thousand Oaks, CA; 1998.

22. McCoy CE, Sayegh J, Alrabah R, Yarris LM: Telesimulation: an innovative tool for health professions education. AEM Educ Train. 2017, 1:132-136. 10.1002/aet2.10015

23. Ohta K, Kurosawa $\mathrm{H}$, Shiima $\mathrm{Y}$, et al.: The effectiveness of remote facilitation in simulation-based pediatric resuscitation training for medical students. Pediatr Emerg Care. 2017, 33:564-569. 10.1097/PEC.0000000000000752 